\title{
Pure choriocarcinoma of the ovary: a case report
}

\author{
Lin Lv' ${ }^{1}$ Kaixuan Yang ${ }^{2}$, Hai Wu' ${ }^{1}$, Jiangyan Lou' ${ }^{1}$ Zhilan Peng ${ }^{1}$ \\ Departments of ${ }^{1}$ Obstetrics and Gynecology and ${ }^{2}$ Pathology, West China Second University Hospital, Sichuan University, Chengdu, \\ Sichuan, China
}

Pure ovarian choriocarcinomas are extremely rare and aggressive tumors which are gestational or non-gestational in origin. Due to the rarity of the tumor, there is a lack of information on the clinicopathologic features, diagnosis, and treatment. We report a case of a pure ovarian choriocarcinoma, likely of non-gestational origin, treated by cytoreductive surgery in combination with post-operative chemotherapy. The patient was free of disease after a 12-month follow-up.

Keywords: Choriocarcinoma, Non-gestational, Ovary

\section{INTRODUCTION}

Pure ovarian choriocarcinomas are extremely rare malignancies which are of gestational or non-gestational in origin. The gestational type may arise from an ectopic ovarian pregnancy or present as a metastasis from a uterine or tubal choriocarcinoma, while the non-gestational type is a rare germ cell tumor with trophoblastic differentiation. The estimated incidence of gestational ovarian choriocarcinomas is 1 in 369 million pregnancies [1]. Non-gestational ovarian choriocarcinomas account $\leq 0.6 \%$ of all ovarian neoplasms; the pure type is extremely uncommon [2]. Due to the rarity of pure ovarian choriocarcinomas, information on the clinicopathologic features, diagnosis, and therapeutic options is limited. Herein we present a case of a pure ovarian choriocarcinoma, likely of non-gestational origin, and discuss the diagnosis and treatment together with a brief review of the literature.

Received Mar. 21, 2010, Revised May 2, 2010, Accepted May 6, 2010

\section{Correspondence to Zhilan Peng}

Department of Obstetrics and Gynecology, West China Second University Hospital, Sichuan University, Chengdu, Sichuan, China. Tel: 86-28-85502391, Fax: 86-28-85559065, E-mail: pengzhilanl|@yahoo.com.cn

\section{CASE REPORT}

A 48-year-old woman was admitted to our department with a 6-month history of irregular vaginal bleeding and a 1-month history of a palpable abdominal mass. She had a normal vaginal delivery at 26 years of age and had no recent history of normal pregnancies, molar gestations, or abortions. The physical examination revealed abdominal tenderness and a fixed mass arising from the pelvis to $3 \mathrm{~cm}$ below the umbilicus. Ultrasound showed a $15-\mathrm{cm}$ solid mass posterior to the uterus, and consistent with an ovarian tumor. The serum levels of tumor markers, with normal values in parentheses, were as follows: $\beta$-human chorionic gonadotropin (hCG), 7,664.3 mIU/mL (<5.0); CA-125, 217.3 U/mL (<35); CA19-9, 18.6 $\mathrm{U} / \mathrm{mL}(<30)$; alpha fetoprotein (AFP), $1.9 \mathrm{ng} / \mathrm{mL}(<20)$; and carcinoembryonic antigen (CEA), $2.5 \mathrm{ng} / \mathrm{mL}(<5)$. There was no evidence of metastasis to other organs.

After written informed consent was obtained, an exploratory laparotomy was undertaken for a suspected ovarian tumor. Intra-operatively, a dark-red, soft, friable, $18 \times 15 \times 14 \mathrm{~cm}$ mass had replaced the right ovary, which was densely adherent to the colon, rectum, appendix, and posterior surface of the uterus. The left ovary and fallopian tube were normal in appearance. There was no ascites within the peritoneal cavity. Peritoneal washings were obtained for cytology. Cytoreductive 
surgery, including a sub-extensive total hysterectomy, bilateral salpingo-oophorectomy, pelvic lymphadenectomy, para-aortic lymph node sampling, omentectomy, appendectomy, and peritoneal biopsies was performed. Optimal debulking was achieved with no macroscopic residual tumor.

Microscopically, the tumor was confirmed to be a pure choriocarcinoma with widespread necrosis (Fig. 1). The appendiceal serosa and peritoneum were identified with tumor invasion. The uterus, left ovary, left fallopian tube, omentum and all of the extirpated lymph nodes were negative for malignancy. Immunohistochemically, the tumor was positive for $\beta$-hCG (Fig. 2A) and weakly positive for placentallike alkaline phosphatase (PLAP) (Fig. 2B). Eighty percent of the tumor cells were strongly positive for Ki-67.

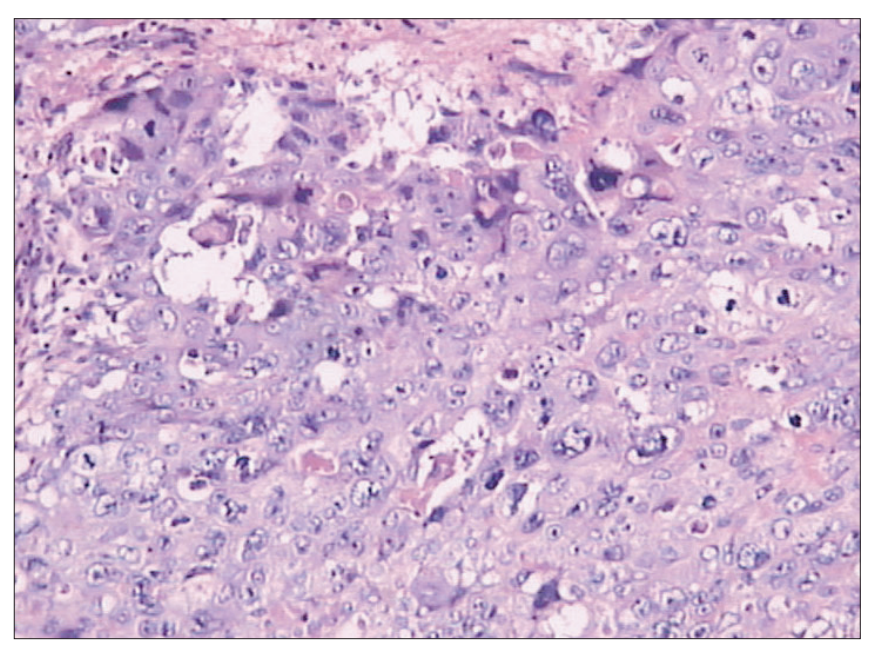

Fig. 1. Microscopic appearance of the tumor shows a pure choriocarcinoma with widespread necrosis $(\mathrm{H} \& \mathrm{E}, \times 200)$.

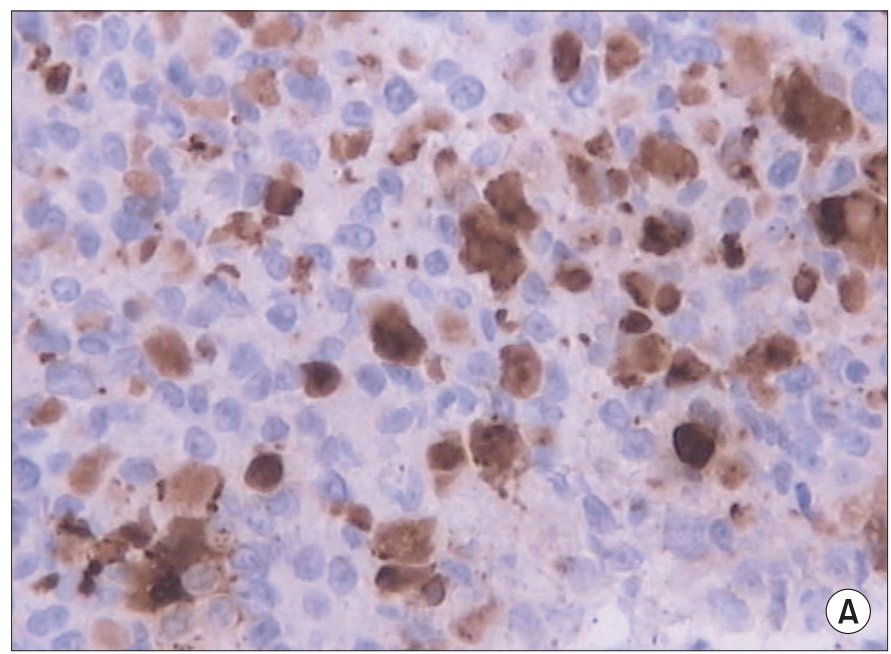

Post-operatively, the patient was treated with bleomycin, etoposide, and cisplatin (BEP) chemotherapy (etoposide [100 $\mathrm{mg} / \mathrm{m}^{2}$ on days 1 and 2], cisplatin [20 $\mathrm{mg} / \mathrm{m}^{2}$ on days $\left.1-5\right]$, and bleomycin [30 mg on day 2]) every 28 days. The serum $\beta$-hCG level decreased to $193.5 \mathrm{mIU} / \mathrm{mL} 1$ week after surgery and was within the normal range after 3 cycles of chemotherapy (Fig. 3). The patient did well after surgery and tolerated 6 cycles of chemotherapy without problems and without evidence of disease after a 12-month follow-up.

\section{DISCUSSION}

Pure ovarian choriocarcinomas are rare, but aggressive tu-

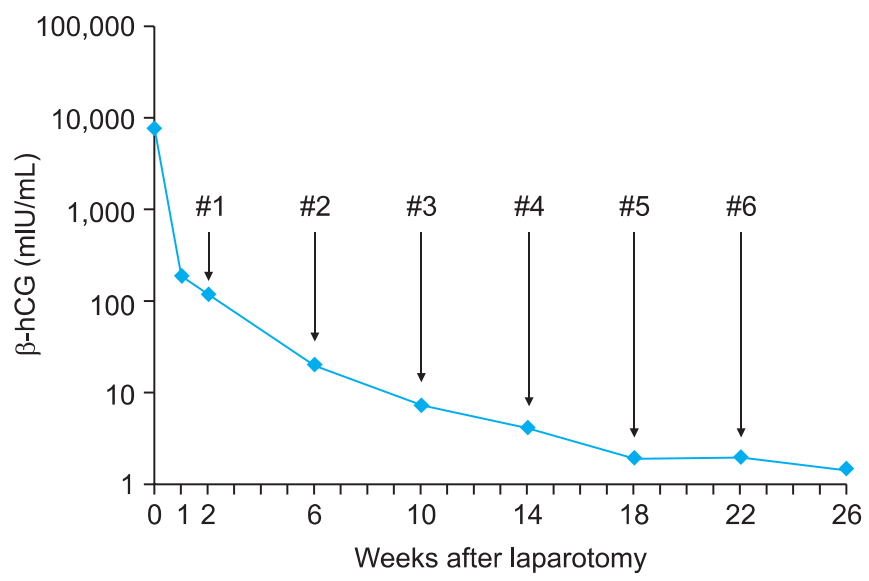

Fig. 3. Decrease in serum $\beta$-human chorionic gonadotropin (hCG) levels after surgery and combination chemotherapy with etoposide, cisplatin and bleomycin. "number indicates the cycle number of chemotherapy.

Fig. 2. Supporting immunohistochemistry shows that the tumor is positive for $\beta$-human chorionic gonadotropin (A) and weakly positive for placental-like alkaline phosphatase (B) (×200). 
mors that pose diagnostic and therapeutic challenges. The pre-operative diagnosis of pure ovarian choriocarcinomas is very difficult, especially for patients in the reproductive age due to the non-specific clinical symptoms which can mimic other more common diseases. In the presence of an adnexal mass with an increased serum $\beta$-hCG level and irregular vaginal bleeding, pure ovarian choriocarcinomas in the childbearing age can be easily mistaken for an ectopic pregnancy pre-operatively $[3,4]$. Some authors have reported the pre-operative diagnosis of pure ovarian choriocarcinomas based on fine needle aspiration cytology [5] or imaging and biologic findings [6]. Confirmation of the diagnosis still relies on the histopathologic findings. Indeed, the presence of malignant cytotrophoblasts and syncytiotrophoblasts, immunohistochemical staining with $\beta-h C G$, and placental lactogen are diagnostic. There are no distinctive ultrastructural or immunohistochemical differences between gestational and non-gestational choriocarcinomas. Thus, to distinguish a gestational ovarian choriocarcinoma from a pure nongestational ovarian choriocarcinoma based on conventional histopathologic studies is not currently possible in the reproductive age group. Molecular genetic analysis is a reliable method for identifying the genetic origin of pure ovarian choriocarcinomas [7-10]. However, since such techniques are always expensive and not generally available in all medical centers, the application is limited. For this very reason, we could not perform molecular genetic analysis on the tumor from our patient. In light of the long duration (22 years) from the antecendent pregnancy, the absence of intrauterine trophoblastic disease, and the relatively low $\beta$-hCG level, we

Table 1. Pure ovarian choriocarcinoma: summary of cases

\begin{tabular}{|c|c|c|c|c|c|c|}
\hline Authors & Age & $\begin{array}{c}\text { Gestational or } \\
\text { non-gestational }\end{array}$ & $\beta-h C G$ & Surgery & Chemotherapy & Outcome \\
\hline Shin et al. [12], 1994 & 45 & Non-gestational & 132,005 & $\mathrm{TAH}, \mathrm{BSO}$ & MAC & 1 yr NED \\
\hline Byeun et al. [13], 1995 & 28 & Non-gestational & 13,378 & RSO & $\mathrm{EMA} / \mathrm{CO}$ & 1 yr NED \\
\hline Lorigan et al. [14], 1996 & 41 & Gestational & 151,500 & $\begin{array}{l}\text { TAH, BSO, } \\
\text { omentectomy }\end{array}$ & BEP, IE & 3 mo NED \\
\hline Kim et al. [15], 1997 & 16 & Non-gestational & 565,000 & $\mathrm{TAH}, \mathrm{BSO}$ & MAC & $\begin{array}{l}\text { Died during } \\
\text { chemotherapy }\end{array}$ \\
\hline Namba et al. [16], 2003 & 37 & Gestational & 990,000 & RSO, & MAC & NED \\
\hline Tsujioka et al. [7] 2003 & 19 & Non-gestational & 110,000 & $\begin{array}{l}\text { LSO, partial omentectomy, } \\
\text { biopsy of right ovary }\end{array}$ & $\mathrm{EMA} / \mathrm{CO}$ & NED \\
\hline Chien et al. [17], 2004 & 21 & Non-gestational & $1,787,052.30$ & LSO, tumor excision & $\mathrm{EMA} / \mathrm{CO}$ & $\begin{array}{l}\text { Died of sepsis } 7 \\
\text { mo after diagnosis }\end{array}$ \\
\hline Balat et al. [3], 2004 & 24 & Non-gestational & $\begin{array}{l}8,968 \text { (when admitted) } \\
45,701 \text { ( } 20 \text { days after } \\
\text { the first operation) }\end{array}$ & $\begin{array}{l}\text { TAH, BSO, infracolic } \\
\text { omentectomy, pelvic } \\
\text { lymphadenectomy }\end{array}$ & BEP & $\begin{array}{l}\text { Died of disease } \\
\text { after the } 1^{\text {st }} \text { cycle } \\
\text { of chemotherapy }\end{array}$ \\
\hline Bazot et al. [6], 2004 & 38 & Non-gestational & $2,460,000$ & $\mathrm{TAH}, \mathrm{BSO}$ & Yes, details NS & 7 yr NED \\
\hline Koo et al. [9], 2006 & 33 & Non-gestational & 185,000 & $\begin{array}{l}\mathrm{AH}, \mathrm{BSO}, \text { omentectomy, } \\
\text { pelvic lymphadenectomy }\end{array}$ & MAC & NED \\
\hline Gerson et al. [18], 2007 & 33 & Gestational & 564,000 & TAH, RSO, LS, splenectomy & $\mathrm{EMA} / \mathrm{CO}$ & $1 \mathrm{yr}$ NED \\
\hline $\begin{array}{l}\text { Yamamoto et al. [10], } \\
2007\end{array}$ & 19 & Non-gestational & 206,949 & LO & $\mathrm{EMA} / \mathrm{CO}$ & 12 mo NED \\
\hline Mood et al. [19], 2009 & 31 & Gestational & More than 1000 & RSO & $\mathrm{EMA} / \mathrm{CE}$ & 7 yr NED \\
\hline Mood et al. [19], 2009 & 32 & Gestational & 5,500 & $\begin{array}{l}\text { TAH, BSO, tumor } \\
\text { debulkation and infracolic } \\
\text { omentectomy }\end{array}$ & $\mathrm{BEP}, \mathrm{EMA} / \mathrm{CE}$ & 5 yr NED \\
\hline $\begin{array}{l}\text { Mishra and Crasta [20], } \\
2008\end{array}$ & 25 & Non-gestational & More than $1,000,000$ & TAH, BSO, omental biopsy & $\begin{array}{l}\text { Yes, one cycle, } \\
\text { details NS }\end{array}$ & Lost follow-up \\
\hline Park et al. [21], 2009 & 55 & Non-gestational & 64,838 & $\begin{array}{l}\text { TAH, BSO, multiple } \\
\text { biopsies }\end{array}$ & BEP & 20 mo NED \\
\hline Gon et al. [22], 2010 & 21 & Non-gestational & 279,000 & RSO & NS & NS \\
\hline
\end{tabular}

hCG, human chorionic gonadotropin; TAH, total abdominal hysterectomy; R, right; L, left; $B$, bilateral; S, salpingectomy; $\mathrm{O}$, oophorectomy; $M A C$, methotrexate, actinomycin-D, cyclophosphamide; EMA/CO, etoposide, methotrexate, actinomycin-D, cyclophosphamide, vincristine; $B E P$, bleomycin, etoposide, cisplatin; IE, ifosfamide, etoposide; EMA/CE, etoposide, methotrexate, actinomycin-D, cisplatin, etoposide; NED, no evidence of disease; NS, not stated. 
suggest that our patient had a pure non-gestational ovarian choriocarcinoma.

We have reviewed the previously reported cases of pure ovarian choriocarcinoma and summarized the details of these cases including $\beta$-hCG level, operation procedures, chemotherapy and outcome. Since Goswami et al. [11] made a detailed summary and analysis about 30 cases of pure non-gestational choriocarcinoma in 2001, we only present cases not mentioned by Goswami et al. [11] or reported after Goswami's study in our article (Table 1). According to the previous reports, it seems that pure ovarian choriocarcinoma responds well to the combination of surgical ablation and post-operative chemotherapy. To date, no definitive treatment modality has been established for pure ovarian choriocarcinomas due to the low incidence. Thus, pure ovarian choriocarcinomas are generally treated by the same protocols used for ovarian germ-cell tumors and gestational trophoblastic disease. In the current case, the treatment included cytoreductive surgery followed by postoperative chemotherapy. Optimal cytoreductive surgery was indispensible in our patient, as demonstrated by the dramatic decline in the serum $\beta$-hCG level post-operatively. There is no consensus on the optimal chemotherapy following surgery. Non-gestational ovarian choriocarcinoma has been found to have a worse prognosis and requires more aggressive chemotherapy compared with gestational ovarian choriocarcinoma. Gestational choriocarcinoma usually responds well to methotrexate-based chemotherapy; however, non-gestational choriocarcinoma may be resistant to this therapy [11]. Because non-gestational choriocarcinoma is considered as a germ cell tumor differentiating to trophoblastic components, a germ cell tumor treatment protocol may be effective $[3,21]$. BEP chemotherapy is the current regimen for germ cell tumors of the ovary [23]. Thus, our patient underwent BEP chemotherapy for a presumed primary pure non-gestational choriocarcinoma. The patient had a good response to the BEP regimen with a satisfactory decrease in the serum $\beta-h C G$ level. There was no evidence of recurrence or metastasis after a 12-month follow-up. Our case provides evidence that cytoreductive surgery in combination with postoperative chemotherapy may be an effective therapeutic strategy for pure ovarian choriocarcinomas. Considering that pure ovarian choriocarcinoma is aggressive with a high risk of metastasis, close follow-up with serum $\beta$-hCG and imaging examinations is essential.

\section{CONFLICT OF INTEREST}

No potential conflict of interest relevant to this article was reported.

\section{REFERENCES}

1. Axe SR, Klein VR, Woodruff JD. Choriocarcinoma of the ovary. Obstet Gynecol 1985;66:111-4.

2. Vance RP, Geisinger KR. Pure nongestational choriocarcinoma of the ovary: report of a case. Cancer 1985;56:23215.

3. Balat O, Kutlar I, Ozkur A, Bakir K, Aksoy F, Ugur MG. Primary pure ovarian choriocarcinoma mimicking ectopic pregnancy: a report of fulminant progression. Tumori 2004; 90:136-8.

4. Chen YX, Xu J, Lv WG, Xie X. Primary ovarian choriocarcinoma mimicking ectopic pregnancy managed with laparoscopy: case report. Eur J Gynaecol Oncol 2008;29:174-6.

5. Naniwadekar MR, Desai SR, Kshirsagar NS, Angarkar NN, Dombale VD, Jagtap SV. Pure choriocarcinoma of ovary diagnosed by fine needle aspiration cytology. Indian J Pathol Microbiol 2009;52:417-20.

6. Bazot M, Cortez A, Sananes S, Buy JN. Imaging of pure primary ovarian choriocarcinoma. AJR Am J Roentgenol 2004;182:1603-4.

7. Tsujioka H, Hamada H, Miyakawa T, Hachisuga T, Kawarabayashi T. A pure nongestational choriocarcinoma of the ovary diagnosed with DNA polymorphism analysis. Gynecol Oncol 2003;89:540-2.

8. Zhao J, Xiang Y, Wan XR, Feng FZ, Cui QC, Yang XY. Molecular genetic analyses of choriocarcinoma. Placenta 2009;30:816-20.

9. Koo HL, Choi J, Kim KR, Kim JH. Pure non-gestational choriocarcinoma of the ovary diagnosed by DNA polymorphism analysis. Pathol Int 2006;56:613-6.

10. Yamamoto $E$, Ino K, Yamamoto $T$, Sumigama S, Nawa A, Nomura $S$, et al. A pure nongestational choriocarcinoma of the ovary diagnosed with short tandem repeat analysis: case report and review of the literature. Int J Gynecol Cancer 2007;17:254-8.

11. Goswami D, Sharma K, Zutshi V, Tempe A, Nigam S. Nongestational pure ovarian choriocarcinoma with contralateral teratoma. Gynecol Oncol 2001;80:262-6.

12. Shin YS, You HI, Lim OR, Park SY, Kim YT, Lee KW. A case of primary ovarian choriocarcinoma. Korean J Obstet Gynecol 1994;37:592-6.

13. Byeun TS, Byeun C, Chung DY, Park TC, Ahn WS, Lee JW, et al. A case of primary ovarian carcinoma. Korean J Obstet 
Gynecol 1995;38:1713-7.

14. Lorigan PC, Grierson AJ, Goepel JR, Coleman RE, Goyns $\mathrm{MH}$. Gestational choriocarcinoma of the ovary diagnosed by analysis of tumour DNA. Cancer Lett 1996;104:27-30.

15. Kim KS, Kim JH, Jung MJ, Oh BC. Primary ovarian nongestational choriocarcinoma in a young woman. Korean J Obstet Gynecol 1997;40:1802-7.

16. Namba A, Nakagawa S, Nakamura N, Takazawa Y, Kugu $\mathrm{K}$, Tsutsumi O, et al. Ovarian choriocarcinoma arising from partial mole as evidenced by deoxyribonucleic acid microsatellite analysis. Obstet Gynecol 2003;102:991-4.

17. Chien SC, Chow SN, Koh LW. Pure primary nongestational choriocarcinoma of the ovary: a case report. Taiwanese J Obstet Gynecol 2004;43:240-2.

18. Gerson RF, Lee EY, Gorman E. Primary extrauterine ovarian choriocarcinoma mistaken for ectopic pregnancy: sonographic imaging findings. AJR Am J Roentgenol
2007;189:W280-3.

19. Izadi Mood N, Samadi N, Rahimi-Moghaddam P, Sarmadi S, Eftekhar Z, Yarandi F. Pure ovarian choriocarcinoma: report of two cases. J Res Med Sci 2009;14:327-30.

20. Mishra SK, Crasta JA. Primary choriocarcinoma of the ovary: a case report. J Clin Diagn Res 2008;2:1207-9.

21. Park SH, Park A, Kim JY, Kwon JH, Koh SB. A case of nongestational choriocarcinoma arising in the ovary of a postmenopausal woman. J Gynecol Oncol 2009;20:192-4.

22. Gon S, Majumdar B, Barui G, Karmakar R, Bhattacharya A. Pure primary non-gestational ovarian choriocarcinoma: a diagnostic dilemma. Indian J Pathol Microbiol 2010;53: $178-80$.

23. Gershenson DM. Management of early ovarian cancer: germ cell and sex cord-stromal tumors. Gynecol Oncol 1994;55:S62-72. 